\title{
The Reliability Analysis of Prickel's Writing Self-Efficacy Scale in Indonesian Context
}

\author{
Lestari Setyowati \\ lestari.setyowati@yahoo.co.id \\ STKIP PGRI Pasuruan
}

Jl. Ki Hajar Dewantara 27-29 Pasuruan, Jawa Timur, Indonesia

Received: January 1, 2016; Accepted: February 28, 2016; Published: March 25, 2016

\begin{abstract}
This study is intended to describe the quality of writing self-efficacy scale when it was applied in foreign language context. The design used is Correlational analysis by using Cronbach Alpha statistical tool. The participants of the study were 55 students of English Education Study program of STKIP PGRI Pasuruan who joined Writing II course and who were randomly chosen to fill out the questionnaire. The data were collected from 10 to 11 September 2014. The result of the study shows that the reliability is $r=.785$, lower than the reliability claimed by the maker $(r=.9249)$. The possible cause of the reliability difference is discussed as well as the recommendation for future researchers.
\end{abstract}

Keywords: self-efficacy, writing, correlational analysis

How to cite this paper: Setyowati, L. (2016). The Reliability Analysis of Prickel's Writing Self-Efficacy Scale in Indonesian Context. Journal on English as a Foreign Language, 6(1), 21-32.

Most researchers believe that motivation plays a crucial factor in students' learning achievement. Without motivation, even individuals who have the most abilities will not be able to achieve their intended goals. Therefore, for the past two decades, cognitive aspects have received particular attention in the educational field, especially in writing context, as researchers have attempted to understand the thought processes underlying the compositions of students. From the writing model proposed motivation also has its own place. It was believed that motivation/affect (feeling or emotion) is especially important to 
writing. It is because there are elements that inspire the writer within this motivation/affect processes, among them are goals, beliefs, and attitudes about the topic. Since Writing is a complex task and a time-consuming activity, concentration, and determination to complete the task are highly required. Selfefficacy beliefs have been found to be vital in energizing students to engage in learning behavior in a wide range of academic, including writing (Kormos, 2012).

Self-efficacy is individual's judgment of capabilities in performing a taskspecific behavior which is based on his her actual accomplishments of success and failures (Linnenbrink \& Pintrich, 2002). Thus, the self-efficacy scale is commonly understood as being very specific; that is, one can have more or less firm self-beliefs in different domains or particular situations of functioning. To measure the students' self-beliefs in writing, a Likert-scale can be used. Likert scale is believed to be able to measure broader attitude and values (Johns, 2010).

Within Indonesian context, it is a common knowledge that writing in a foreign language is a battle for novice FL learners. With its complexity, many novice FL writers often find that they are not confident enough to complete the writing task. However, to say that they have no motivation to write is degrading their potentials, while saying otherwise is overestimating their capabilities.

To be able to know the students' individual beliefs about their own capabilities in writing, there should be a scale that can measure the student writers self-efficacy. Unfortunately, in Indonesia, there is not much attention given to the development of the students' self-efficacy beliefs' scale. Since developing a reliable writing self-efficacy scale questionnaire is costly, energy and time consuming, it is suggested that writing researchers use a readily developed self-efficacy scale made by other researchers more acknowledgeable in that field. Among the many other self-efficacy scales found in the literature, Prickel's (1994) writing self-efficacy is among them.

Prickel (1994) developed his writing self-efficacy in his dissertation for the purpose of constructing a reliable and valid scale for measuring writing selfefficacy beliefs for adult level by means of series of testing to selected group of adult basic education students. Unfortunately, very scarce literature informs other researchers whether it is sufficiently reliable to be used in foreign language context. This study is intended to describe Prickel's writing selfefficacy questionnaire scale reliability when it is applied in FL context.

In terms of self-efficacy questionnaires in writing, some researchers in cognitive and writing field used general self-efficacy questionnaires which sometimes did not measure writing self-efficacy at all. For example, a research conducted by Aidinlou and Far (2014) which measure the relationship between 
self-efficacy beliefs, writing strategies, and the correct use of conjunction in Iranian EFL learners. In their research, they used "Self-efficacy Questionnaire" which originally was used to measure self-regulation trait developed by $\mathrm{O}^{\prime} \mathrm{Neil}$ and Herl (in Adinlou \& Far, 2014). There were 32 items in the questionnaire which covers four constructs, namely Planning, Self-checking, Effort, and Selfefficacy. To serve the purpose of their research, these researchers then chose and modified the items related to self-efficacy only.

Another type of general self-efficacy scale which is quite popular among Iranian writing researchers is the one developed by Sherer, known as Sherer General Self-Efficacy Scale (SGSES). Fatemi and Vahidnia (2013) used SGSES developed by Sherer et al. in Fatemi and Vahidnia (2013) to predict their participants' performance in writing. The result shows that learners' writing performance is correlated with their general self-efficacy beliefs. While other research conducted by Hashemnejad, et al. (2014), who also used this scale to find out the relationship between self-efficacy and writing performance across gender, shows different finding. The result of their research shows that writing performance is not correlated with self-efficacy across gender. The results of these studies mentioned above should be taken cautiously because SGSES is not used specifically to measure learners' writing self-efficacy. SGSES was basically used to "predict motivational reactions and behaviors across a variety work domains" (Imam, 2007).

Having said these, it is indeed necessary to have a self-efficacy scale which is really intended to measure what is supposed to measure. General selfefficacy scale might not be appropriate to measure the students' self-efficacy belief as it is not intended to measure writing as a specific task. Using general self-efficacy scale might give wrong information about the actual belief of the students' capabilities in the writing task.

\section{METHOD}

The design used in this study is a correlational study to find the internal consistency of the Likert questions in the questionnaire that form a scale. The Writing Self-Efficacy Scale questionnaire was developed by Prickel (1994).The scale has 25 items with 5 point scales ranging from A to E: (A) Strongly Disagree with 1 point, (B) Disagree with 2 points, (C) Unsure with 3 points. (D) Agree with 4 points, and (E) Strongly Agree with 5 points. Thus, the highest score for the self-efficacy scale is 125 and the lowest score would be 25. Prickel (1994) himself has established evidence of the scale's validity and reliability (0.9249) which indicated a significantly high level of consistency of this instrument. He, however, had admitted that further analyses were needed to find out some evidence of unidimensionality. Unidimensionality means having only one dimension. In this case, Prickel (1994) believes that the concept of selfJournal on English as a Foreign Language, 6(1), 21-30

Copyright (C) 2016 by JEFL, p-ISSN 2088-1657; e-ISSN 2502-6615 
efficacy is indeed unidimensional in reality. Thus, he developed a self-efficacy scale which measures only one construct, the writing self-efficacy. Yet, he admitted that more evidence needs to be provided to ensure that the scale he developed is indeed unidimensional. Eventough Prickel (1994) has tested the reliability and the validity of the questionnaire, a try out is conducted to find out whether the questionnaire needs further improvement in terms of its reliability.

The subjects of the try-out were the third semester of the English Study Program students of STKIP PGRI Pasuruan. Among the four classes of Writing II, the researcher chose randomly the subjects to fill out the questionnaire. There were 60 questionnaires distributed to two classes of Writing II, but only 55 questionnaires returned to the researcher. The data were collected in 10 and 11 September 2014. Cronbach Alpha statistical tool of SPSS 20 was applied as it was aimed at measuring the internal consistency of Likert questions in the questionnaire that form a scale. Another instrument used in the study was interview by using think-aloud protocols to gain feedback on the students' feeling when they were filling out the questionnaires as well as its clarity and difficulty.

\section{FINDINGS}

After the questionnaires scale were administered to 55 students for the try out, the result of the computation shows that the Cronbach Alpha value is 0.785. See Table 1.

Table 1. Reliability Statistics

\begin{tabular}{ccc}
\hline Cronbach's Alpha & $\begin{array}{c}\text { Cronbach's Alpha Based on Standardized } \\
\text { Items }\end{array}$ & N of Items \\
\hline .785 & .781 & 25 \\
\hline
\end{tabular}

The reliability statistics indicated a high internal consistency with this specific sample used in this study. The result of the computation was a little bit lower than the original value of internal consistency when it was tested by Prickel (1994) which is 0.9249. Each item in the questionnaire was then computed to see its quality. See Table 2.

The report of the quality of each questionnaire item can be seen from the third column which is the correlation between a particular item and the sum of the rest of the items. This column informs how well a particular item "goes along with" the rest of the items. In the output above, the best item appears to be Q2, with an item-total correlation of $r=.624$. The item with the lowest itemtotal correlation is Q24 ( $r=.078)$. Q24 number is close to zero which informs that item number 24 in the questionnaire needs further reconsideration as it is not measuring the same thing as the rest of the items.

Journal on English as a Foreign Language, 6(1), 21-30

Copyright (C) 2016 by JEFL, p-ISSN 2088-1657; e-ISSN 2502-6615 
The last column gives the most important information of the quality of Prickel's scale. "Alpha if Item Deleted" column estimates what the Cronbach's alpha would be if a particular item is deleted from the scale. A higher alpha value should indicate more reliability. In this case, any number in the last column should not be higher than the current alpha of the whole scale: .785 (Table 1). However, Q24 shows something interesting. If this item is deleted, the Cronbach alpha of this scale would jump from .785 to .789 which shows that, again, this item needs further reconsideration, either rewording it or dropping it.

Table 2. Item-Total Statistics

\begin{tabular}{cccccc}
\hline Items & $\begin{array}{c}\text { Scale Mean if } \\
\text { Item Deleted }\end{array}$ & $\begin{array}{c}\text { Scale Variance } \\
\text { if Item Deleted }\end{array}$ & $\begin{array}{c}\text { Corrected Item- } \\
\text { Total } \\
\text { Correlation }\end{array}$ & $\begin{array}{c}\text { Squared } \\
\text { Multiple } \\
\text { Correlation }\end{array}$ & $\begin{array}{c}\text { Cronbach's } \\
\text { Alpha if Item } \\
\text { Deleted }\end{array}$ \\
\hline Q1 & 76.7636 & 101.147 & .330 & .621 & .777 \\
\hline Q2 & 76.7818 & 90.655 & .624 & .798 & .756 \\
\hline Q3 & 76.5091 & 100.218 & .382 & .619 & .774 \\
\hline Q4 & 76.1818 & 102.707 & .285 & .701 & .779 \\
\hline Q5 & 76.9091 & 99.603 & .398 & .731 & .773 \\
\hline Q6 & 76.4182 & 102.026 & .339 & .675 & .777 \\
\hline Q7 & 76.5455 & 98.549 & .389 & .709 & .773 \\
\hline Q8 & 76.5636 & 101.843 & .283 & .578 & .779 \\
\hline Q9 & 77.1636 & 103.325 & .208 & .754 & .783 \\
\hline Q10 & 76.5818 & 100.877 & .367 & .692 & .775 \\
\hline Q11 & 76.4909 & 101.921 & .286 & .532 & .779 \\
\hline Q12 & 76.8000 & 102.163 & .228 & .655 & .783 \\
\hline Q13 & 76.1091 & 101.692 & .327 & .453 & .777 \\
\hline Q14 & 76.8545 & 98.312 & .391 & .666 & .773 \\
\hline Q15 & 76.5273 & 102.328 & .276 & .669 & .780 \\
\hline Q16 & 76.5273 & 98.217 & .382 & .685 & .774 \\
\hline Q17 & 76.3273 & 101.409 & .294 & .388 & .779 \\
\hline Q18 & 76.5818 & 101.989 & .279 & .521 & .780 \\
\hline Q19 & 76.1273 & 100.335 & .410 & .549 & .773 \\
\hline Q20 & 76.4000 & 103.022 & .257 & .674 & .781 \\
\hline Q21 & 76.2000 & 99.607 & .446 & .588 & .771 \\
\hline Q22 & 76.8545 & 104.719 & .160 & .438 & .785 \\
\hline Q23 & 76.4909 & 103.514 & .201 & .655 & .784 \\
\hline Q24 & 76.7273 & 106.276 & .078 & .704 & .789 \\
\hline Q25 & 76.4545 & 104.178 & .212 & .611 & .783 \\
\hline & & & & & \\
\hline
\end{tabular}

It was found out from the result of the interview through think aloud protocol that the items in the questionnaire are clear and understandable. One 
of the indicators that the items are understandable and do not cause confusion is none of the students chose two answers in one item. However, looking at the students' answer, many of them chose to circle their option while others preferred to cross it. When the instructions in the questionnaire were read more carefully, it became obvious why there were differences in the response. This is all because no clear instruction was given whether the option should be circled or crossed.

\section{DISCUSSION}

It is not easy to develop a writing self-efficacy scale that can measure learners' beliefs and attitudes in writing. One way to overcome this difficulty is using the available scale made by other researchers. However, one cannot blindly use the scale obtained from a published source without having more information of its reliability evidence. In this case, Prickel (1994) has developed a writing self-efficacy questionnaire in his dissertation to be used by other researchers interested in measuring learners' self-efficacy belief.

After the questionnaires were tested to 55 students, the result of this try out shows that the reliability is $(r=.785)$. The result of Cronbach Alpha reliability analysis as stated by Tavakol and Dennick (2011) has the acceptable value which is ranging from 0.70 to 0.95 . Although the result of the computation was a little bit lower than the original value of internal consistency when it was tested by Prickel (1994) which is 0.9249, the researcher believed that this self-efficacy scale developed by Prickel (1994) has served its function to be sufficiently reliable for measuring writing self-efficacy level for adult students. Prickel is able to reach a very high internal consistency (0.9249) because he used more sample to test the reliability of this scale in which he administered it to six community college students in Oregon with a total number of 239 respondents while in this research, the researcher used only 55 students. The result of Cronbach Alpha computation also shows that one item in the questionnaire $(\mathrm{Q} 24)$ needs further consideration to be used, either rewording it or removing it from the list. Removal of this item can increase the reliability coefficient of the overall scale into $r=.789$.

For future researchers who wish to find out the FL students' self-efficacy, Prickel's (1994) scale can be used to measure this attitude. Future researchers need to be aware that the questionnaire is intended to measure the students' positive attitude toward their self-efficacy in writing. Because of that, before analyzing the questionnaire, it should be checked whether all questions have shown a positive direction. Not all items in this questionnaire, however, show positive directions. Some items in Prickel's self-efficacy questionnaire show negative directions as the words are negatively worded although the items 
actually say the opposite of what was intended. For example item number 2 in the questionnaire which says: I believe that errors in punctuation and grammar stop me from being a good writer.

The answer to item number 2 should be "strongly disagree" which is typically equal to 1 , which seems to be strange since "strongly disagree" is indeed the intended response to the item. Therefore, to show positive direction, reverse coding should be made since the intention of the self-efficacy questionnaire is to show the positive direction of the respondents' self-belief in writing. Reverse coding should be otherwise. In the case of the example item above, the appropriate response should be "strongly disagree" which scores 5 . If some items are not reversely coded, there might be wrong information gained from the questionnaire result.

\section{CONCLUSION}

Having said all these, it can be concluded that Prickel's writing selfefficacy questionnaire can be used to measure FL learner's writing self-efficacy belief in Indonesian context with some minor revisions in the instruction, not on the content of the scale itself. With Cronbach Alpha coefficient $r=.785$, this questionnaire is sufficiently reliable to give learners' information about their attitude in writing.

However, some careful steps should be taken if one wishes to use this in the research in relation to writing self-efficacy and writing performance. Among them are the reverse coding system before tallying the result of each item. Secondly, one should reconsider the omission of item \#24. It is estimated that the deletion of this item might increase the reliability coefficient .004 higher. Being able to measure the students' attitude and belief in writing by employing a reliable tool can provide more valid information on the nature of how student-writers complete their writing task. Although the hard evidence of the reliability of writing self-efficacy scale developed by Prickel (1994) has been provided, it does not mean that this scale is the only one available in the literature as there are many other writing self-efficacy scales that writing researchers can select. Researchers can choose one appropriate for their purpose to answer the research problem.

\section{REFERENCES}

Adinlou, N. A., \& Far, L. M. (2014). The relationship of self-efficacy beliefs, writing strategies, and the correct use of conjunctions in Iranian EFL learners. International Journal of Applied Linguistics \& English Literature, $3(4), 221-227$. 
Fatemi, A. H., E Vahidnia, F. (2013). An investigation into Iranian EFL learners' level of writing self-efficacy.Theory and Practice in Language Studies, 3(9), 1698-1704.

Hashemnejad, F., Zoghi, M., \& Amini, D. (2014).The relationship between selfefficacy and writing performance across genders. Theory and Practice in Language Studies, 4(5), 1045-1052.

Imam, S. S. (2007). Sherer Et Al. General Self-Efficacy Scale: Dimensionality, Internal Consistency, And Temporal Stability. Proceedings of the Redesigning Pedagogy: Culture, Knowledge, and Understanding Conference, Singapore, May 2007. (Online), Retrieved on 30 April 2016 from http://citeseerx.ist.psu.edu/viewdoc/download?doi=

10.1.1.507.1337 $\&$ rep $=$ rep $1 \&$ type $=$ pdf

Johns, R. (2010). Likert items and scales. SQB method fact sheet 1. (Online), $\begin{array}{lllll}\text { Retrieved on } & 20 & \text { May } & 2013 & \text { from }\end{array}$ http://surveynet.ac.uk/sqb/datacollection/likertfactsheet.pdf

Kormos, J. (2012). The role of individual differences in L2 writing. Journal of Second Language Writing, 21(4), 390-403.

Linnenbrink, E. A., \&. Pintrich, P. R. (2002). Motivation as an enabler for academic success. School Psychology Review, 31(3), 313-327.

Prickel, D. O. (1994).The development and validation of a writing self-efficacy scale for adult basic writers and its use in correlational analysis. Published Dissertation. Oregon State University. (Online), Retrieved 22 August 2013 from http://r.library.oregonstate.edu/xmlui/handle $/ 1957 / 32102$

Tavakol, M., \& Dennick, R. (2011). Making sense of Cronbach alpha. International Journal of Medical Education, 2, 53-55.

\section{Author's Brief CV}

Lestari Setyowati is a full-time lecturer of College of Teacher Training and Education (STKIP) PGRI Pasuruan, East Java, Indonesia. She has been teaching in this institution from 1999 until present. She earned her Undergraduate degree (2000), Master degree (2005), and Doctoral degree (2016) in ELT from State University of Malang. Her subjects interest are Teaching EFL Writing, Instructional media in EFL context, literature, and ELT. Email/HP: lestari.setyowati@yahoo.co.id_085790312008. 
Appendix: Writing Self-Efficacy Scale

\section{Writing Self-Efficacy Scale}

By Donald E Prickle (1994)

\section{Directions:}

The statements, which follow, ask about your beliefs about writing. Please answer these statements as honestly as you can. Respond in terms of your PRESENT circumstances as a student and writer. In other words, answer in terms of what is true for you right now, NOT in terms of what you hope for the future. Please indicate the degree to which you feel confident in performing each statement today by giving a circle to the letter on the answer sheet that corresponds to your feelings on the following scale below:

$\mathrm{A}=$ If you strongly agree (SA); you always feel this way.

$\mathrm{B}=$ If you agree (A); you feel this way most of the time.

$\mathrm{C}=$ If you are unsure (U) how you feel; you are mostly undecided.

$\mathrm{D}=$ If you disagree (D); you don't feel this way very often.

$\mathrm{E}=$ If you strongly disagree (SD); you never feel this way.

Before you begin, here is an example. Suppose you were asked to respond to the following statement:

I believe I can clearly express my ideas in sentences.

Suppose you feel you have no problems writing a good sentence. What may be true for you right now is that you are able to write good sentences. Therefore A proper response would be: $\mathrm{A}=$ strongly agree.

Circle the letter correspond to your feeling

\begin{tabular}{clccccc}
\hline No & \multicolumn{1}{c}{ Statement } & SA & A & U & D & SD \\
\hline 1 & I am capable of writing good essays. & A & B & C & D & E \\
\hline 2 & $\begin{array}{l}\text { I believe that errors in punctuation and grammar } \\
\text { stop me from being a good writer. }\end{array}$ & A & B & C & D & E \\
\hline 3 & $\begin{array}{l}\text { I am confident that my writing is understood by } \\
\text { those who read it. }\end{array}$ & A & B & C & D & E \\
\hline 4 & $\begin{array}{l}\text { When writing, I am confident that I can think of } \\
\text { words to express my ideas. }\end{array}$ & A & B & C & D & E \\
\hline 5 & $\begin{array}{l}\text { When I write a story or a paragraph, I have } \\
\text { confidence in ending it with a clear statement. }\end{array}$ & A & B & C & D & E \\
\hline 6 & $\begin{array}{l}\text { I am confident in making sentences that relate to } \\
\text { each other. }\end{array}$ & A & B & C & D & E \\
\hline 7 & $\begin{array}{l}\text { I am confident in arguing and defending my ideas } \\
\text { in writing. }\end{array}$ & A & B & C & D & E \\
\hline
\end{tabular}

Journal on English as a Foreign Language, 6(1), 21-30

Copyright @ 2016 by JEFL, p-ISSN 2088-1657; e-ISSN 2502-6615 


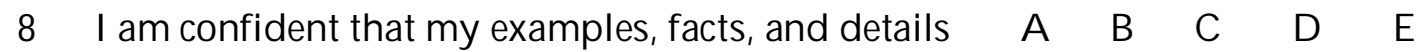
support my written ideas.

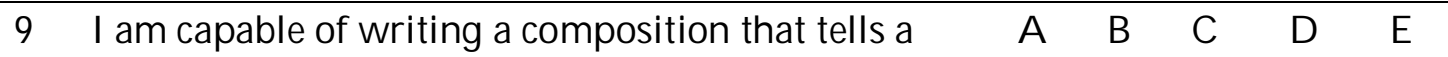
story (for example, a car accident; build a house; cook a three-course meal).

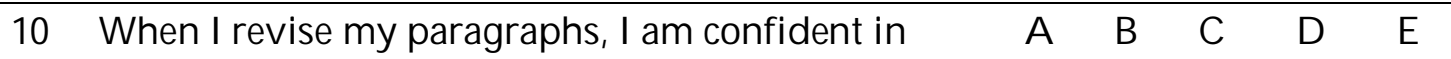
finding my spelling and punctuation errors.

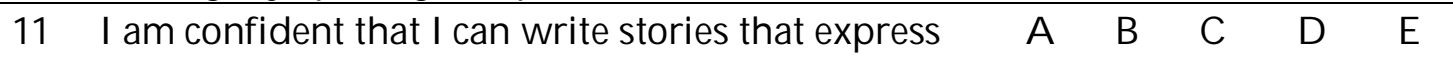
my ideas.

\begin{tabular}{lllllll}
\hline 12 & I believe I can clearly express my ideas in sentences & A & B & C & D & E \\
\hline 13 & I am confident that I can do creative writing such & A & B & C & D & E
\end{tabular}
as poetry, plays, short stories, poems.

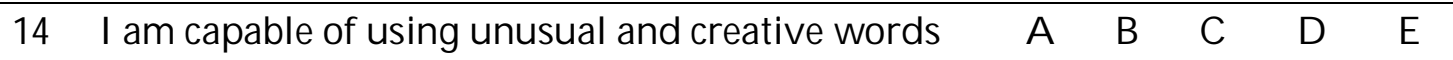
in my writing.

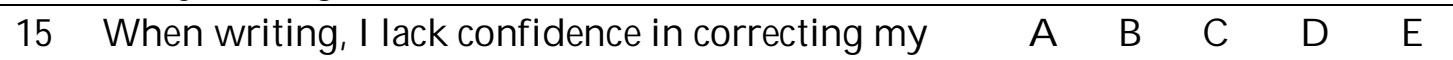
own errors.

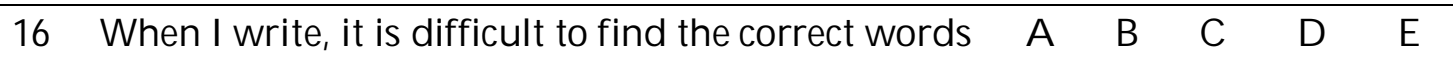
to express my ideas.

\begin{tabular}{lllllll}
\hline 17 & I am not confident in writing an essay or story & A & B & C & D & E \\
\hline 18 & $\begin{array}{l}\text { When I write, I find it hard to give reasons for my } \\
\text { views. }\end{array}$ & A & B & C & D & E \\
\hline 19 & I am not confident that I'm good at writing. & A & B & C & D & E \\
\hline 20 & $\begin{array}{l}\text { I am not confident in writing clear answers to test } \\
\text { and/or exam Questions. }\end{array}$ & A & B & C & D & E \\
\hline 21 & $\begin{array}{l}\text { I am not confident in finding my own writing } \\
\text { errors. }\end{array}$ & A & B & C & D & E \\
\hline 22 & I lack confidence in organizing my ideas. & A & B & C & D & E \\
\hline 23 & $\begin{array}{l}\text { I have difficulty in writing a good beginning } \\
\text { sentence. }\end{array}$ & A & B & C & D & E \\
\hline 24 & When writing, I am unable to organize my ideas. & A & B & C & D & E \\
\hline 25 & $\begin{array}{l}\text { I am unable to clearly state the main idea when I } \\
\text { write a paragraph. }\end{array}$ & A & B & C & D & E \\
\hline
\end{tabular}

THANK YOU FOR PARTICIPATION 